\title{
ACTUALIZACIONES
}

\section{MANIFESTACIONES DERMATOLÓGICAS ASOCIADAS A DIABETES MELLITUS}

\section{SKIN MANIFESTATIONS ASSOCIATED WITH DIABETES MELLITUS}

Luis Pablo Duque Jordán'

Norma Ferrari $^{2}$

\section{GENERALIDADES}

La diabetes mellitus (DM) de larga evolución con mal control metabólico puede producir permanentes e irreversibles cambios funcionales y daños en órganos y tejidos provocando, de este modo, complicaciones que principalmente resultan de anormalidades bioquímicas, estructurales y funcionales. Se ha asociado de forma causal el pobre control glucémico y el desarrollo y progresión de complicaciones microvasculares (retinopatía, nefropatía y neuropatía); en virtud de las complicaciones en la microvasculatura, cualquier sistema u órgano puede ser afectado y la piel no es la excepción ${ }^{1-3}$.

Las manifestaciones cutáneas de la diabetes mellitus son numerosas y variadas ${ }^{4}$, la frecuencia de las afecciones cutáneas en las personas diabéticas oscila entre el 30 y el 70\%, aparentemente sin diferencia entre DM1 y DM2 ${ }^{5-7}$, pero si se consideran los efectos metabólicos sobre la microcirculación, los cambios en el colágeno de la piel y los relacionados a neuropatía, estas cifras aumentarían y llegarían al $100 \%$ ?

Se postula que los pacientes diabéticos tipo 2 con mal control metabólico desarrollan con más frecuencia infecciones cutáneas, mientras que aquellos con DM1 padecen frecuentemente lesiones cutáneas del tipo autoinmune, como alopecia areata, vitiligo y liquen plano ${ }^{8-9}$.

La piel posee un doble origen embriológico ectomesodérmico, por lo que se relaciona con todos

\footnotetext{
${ }^{1}$ Escuela de Graduados de la Sociedad Argentina de Diabetes (SAD), 2013

2 Médica de la División Diabetología. Hospital de Clínicas José de San Martín, CABA (mentora)

E-mail: Ipduque@hotmail.com. Escuela de Graduados de la SAD Monografía premiada. Escuela de Graduados de la SAD, 2013
}

los órganos y sistemas del organismo. Es por esto que puede reflejar alteraciones sistémicas, existiendo algunos marcadores dermatológicos bien reconocidos que pueden preceder o acompañar al diagnóstico de una enfermedad sistémica como es la DM. La piel comparte tanto los efectos de las alteraciones metabólicas como de las complicaciones degenerativas crónicas ${ }^{10}$. Es un tejido metabólicamente activo, donde la insulina y otros nutrientes circulantes determinan los procesos de biosíntesis. En los pacientes diabéticos la piel está sometida a los efectos directos de la hiperglucemia y al déficit o resistencia a la insulina. La afectación macro y microvascular unida a la neuropatía autonómica y sensorial provocan disminución de las defensas de la piel, por lo cual ésta se hace más vulnerable a los agresores externos ${ }^{11}$.

Aunque no se conocen con exactitud las causas de la aparición de todas las manifestaciones dermatológicas que se observan en los pacientes con DM, se sabe que muchas se relacionan con alteraciones fisiopatológicas y bioquímicas que se mencionan a continuación.

1. Metabolización de la glucosa por vías no insulinodependientes: a) vía de los polioles con aumento en la producción de sorbitol; b) autooxidación de la glucosa que aumenta las especies reactivas del oxígeno; c) glucosilación no enzimática de las proteínas; d) aumento del diacil glicerol (DAG) con sobre-estimulación de la PKC.

2. Cambios del colágeno que le confieren mayor dureza, menor solubilidad y más resistencia a la digestión enzimática.

3. Alteraciones en la microvasculatura.

4. Neuropatía periférica diabética, ${ }^{7,12-16}$.

Las lesiones en la piel pueden variar de gra- 
vedad, desde leves hasta sumamente serias y amenazar la vida del paciente. No hay lesiones patognomónicas en la diabetes y agruparlas es difícil y controversial; existen diversas clasificaciones sobre las lesiones dermatológicas de los pacientes diabéticos pero no se ha llegado a un consenso o unificación de criterios. Luego de hacer una revisión de las clasificaciones que postulan diversos autores ${ }^{4,13,17-22}$, se presenta un resumen orientado a los aspectos clínicos en cinco grandes grupos: a) afecciones cutáneas con relativa o fuerte asociación con DM; b) afecciones de la piel relacionadas con un origen infeccioso; c) dermatosis relacionadas con las complicaciones de la DM; d) manifestaciones cutáneas relacionadas con el tratamiento de la DM; e) otras manifestaciones. Realizaremos un resumen de la monografía con énfasis en la descripción clínica y su relación con la diabetes de las principales manifestaciones dermatológicas asociadas a esta enfermedad.

\section{Manifestaciones dermatológicas asociadas a diabetes mellitus}

\section{Con relativa o fuerte asociación a DM}

- Dermopatía diabética.

- Necrobiosis lipoídica.

- Ampolla diabética (bullosis diabeticorum).

- Granuloma anular diseminado.

- Síndrome de engrosamiento cutáneo.

a) Escleredema diabético.

b) Piel cérea y movilidad articular.

c) Empedrado digital.

- Piel amarilla.

- Acantosis nigricans.

- Vitiligo.

- Liquen plano.

- Xantomas eruptivos.

- Dermatosis perforantes adquiridas.

- Foliculitis perforante.

- Enfermedad de Kyrle.

- Alopecia areata.

- Siringoma de células claras.

- Psoriasis.

\section{Relacionadas con un origen infeccioso}

- Infecciones micóticas.
a) Dermatofitosis.
b) Candidiasis.
c) Mucormicosis rinocerebral.

- Infecciones bacterianas.
a) Piodermitis.
b) Eritrasma.
c) Infección necrotizante de tejidos blandos.
d) Otitis externa maligna por Pseudomona auriginosa.

Relacionadas con las complicaciones de la DM

- Neuropatía diabética.

- Angiopatía diabética.

- Pie diabético.

\section{Relacionadas con el tratamiento de la DM}

- Trastornos inducidos por insulina.

- Trastornos inducidos por antidiabéticos orales.

\section{Otras manifestaciones}

- Síndrome de Achard Thiers.

- Síndrome del Glucagonoma.

- Síndrome de Alezzandrini.

- Porfiria cutánea tardía.

- Hemocromatosis.

- Prurito.

- Pénfigo buloso.

- Hipomelanosis idiopática guttata.

\section{DERMATOSIS CON RELATIVA $O$ FUERTE ASOCIACIÓN CON DIABETES}

\section{Dermopatía diabética ${ }^{23-27}$}

También conocida como dermopatía de Binkley o máculas pretibiales pigmentadas, es considerada por algunos autores como la manifestación cutánea más frecuente en la DM, aunque no es patognomónica. Con una incidencia que ronda entre el 50 y el $80 \%$, afecta a pacientes con ambos tipos de DM y predomina en los hombres en un $70 \%$ más con respecto a las mujeres; se asocia con mayor frecuencia en pacientes mayores de 50 años y con larga evolución de la enfermedad. Se ha asociado a complicaciones microvasculares, por lo que se puede considerar un marcador de cronicidad y progresión.

Se caracteriza por máculas hiperpigmentadas irregulares, ovales o circulares, atróficas, de 5 a 12 $\mathrm{mm}$ de diámetro, de límites netos, sin escamas ni costras en su superficie, asintomáticas bilaterales no simétricas, apareciendo en forma aislada o agrupadas en la cara anterior de las piernas y menos frecuentemente en los antebrazos, muslos y pies (Figura 1). 


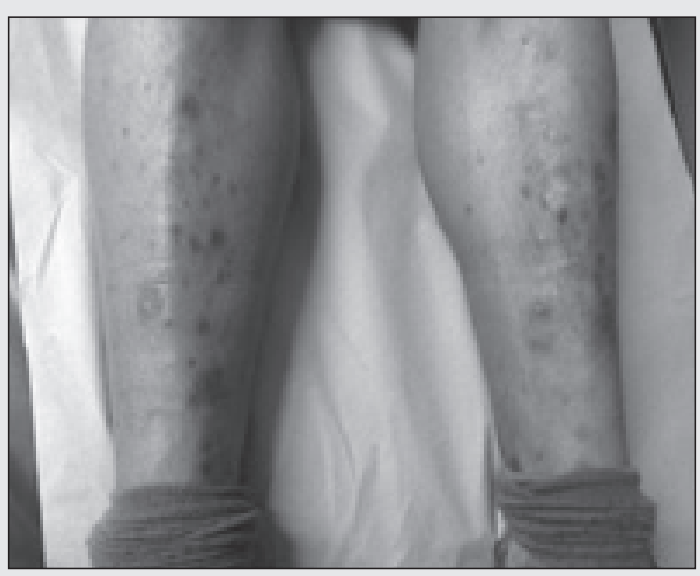

Figura 1: Dermopatía diabética. Imagen propia.

\section{Necrobiosis lipoidea diabeticorum ${ }^{7,13,28-34}$}

También puede llamarse necrobiosis lipoídica, es infrecuente y estrechamente relacionada con DM y la intolerancia a la glucosa; aparece con una prevalencia en los pacientes ya con diagnóstico de DM de entre el 0,3 al 1,6\%, afecta a ambos tipos de DM, es tres veces más frecuente en mujeres, de comienzo aproximado de los 30 años, aunque en aquellos con DM1 puede aparecer más temprano (cerca de los 22 años). Su aparición puede preceder al diagnóstico de DM en el 15\% de los casos en un promedio de dos años; en el $25 \%$ puede aparecer simultáneamente y en el $60 \%$ aparece en pacientes con DM ya diagnosticada. Se postula que hasta el $50 \%$ de los pacientes con necrobiosis lipoídica y DM presentará una o más complicaciones microvasculares.

Es asintomática, comienza como una pequeña placa o nódulo elevado de coloración eritematosa o marrón de bordes bien delimitados, aumentando progresivamente de tamaño de manera centrífuga; el área central adquiere un color marrón-amarillento y aspecto atrófico con múltiples telangiectasias en su superficie. Se localiza característicamente hasta en un $85 \%$ de los casos en regiones pretibiales y caras laterales de ambas piernas, de forma individual o múltiple (Figura 2).

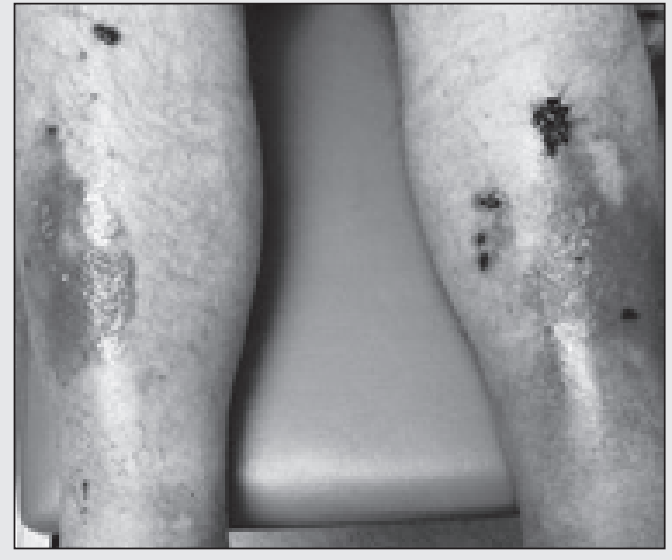

Figura 2: Necrobiosis lipoidea diabeticorum. Imagen propia.

\section{Ampolla diabética ${ }^{13,23-24,35-38}$}

La formación espontánea de ampollas es poco frecuente pero es un marcador distintivo de la DM. Del 0,5 al $1 \%$ de los pacientes con DM desarrolla estas lesiones y su frecuencia aumenta con los años. Algunos autores señalan mayor incidencia en pacientes con DM1 y se reportan en aquellos de entre 40 y 77 años, observándose con mayor frecuencia en los hombres con larga evolución de la enfermedad. Se relaciona con neuropatía, vasculopatía y retinopatía.

Las ampollas aparecen de forma espontánea, sin el antecedente de trauma o infección, a menudo durante la noche y se presentan como ampollas (hasta $10 \mathrm{~mm}$ de diámetro) o bulas (de uno a varios centímetros de diámetro) iniciándose con una o varias lesiones tensas que posteriormente se agrandan y se tornan flácidas, con contenido claro y estéril, generalmente indoloras, sin eritema circundante que se resuelven espontáneamente de dos a cinco semanas. Se localizan generalmente de forma bilateral en las extremidades, siendo más frecuentes en los dedos de los pies o manos, talones o cara anterior de la tibia (Figura 3). 


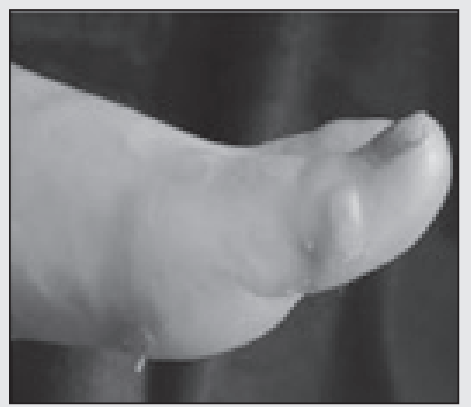

Figura 3: Ampolla diabética. Tomado y adaptado de: www.drpurbit.com.

\section{Granuloma anular $9,21,25,36,39-42$}

El granuloma anular (GA) es una dermatosis inflamatoria, crónica y benigna, de etiología desconocida y usualmente autolimitada. La asociación entre DM y GA es aún controvertida, puede observarse en pacientes con DM1 y DM2; se ha demostrado la asociación de GA en su forma diseminada con DM especialmente en pacientes de edad avanzada. La forma localizada de GA se ha asociado con DM entre un 2 y un 9\% mientras que en adultos jóvenes la forma diseminada se ha asociado con mayor frecuencia a DM en un 10 a un $30 \%$. El GA generalizado en pacientes diabéticos se presenta cerca de los 50 años y predomina en las mujeres con una relación de 2:1.

EI GA en su forma localizada se presenta como pápulas o placas de distribución anular de bordes netos con centro deprimido. Se inician como pequeñas pápulas eritematosas, redondeadas, ligeramente elevadas, de consistencia firme que crecen en forma centrípeta; las lesiones persisten en la periferia, generalmente son de color rosado, blanco amarillento o del color de la piel normal, asintomáticas que pueden desaparecer sin dejar cicatriz. Comúnmente se localizan en el dorso de la mano y los pies. El GA en su forma diseminada se caracteriza por una erupción simétrica de cientos de pápulas diminutas que pueden aparecer por toda la superficie corporal (Figura 4).

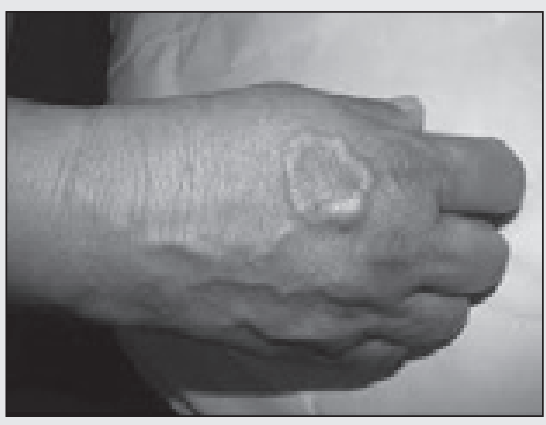

Figura 4: Granuloma anular localizado. Tomado y adaptado de: Corigliano M, Achembach RE. Granuloma anular: un desafío diagnóstico y terapéutico. Revista Argentina de Dermatología 2012; 93(4).

\section{Síndrome de engrosamiento cutáneo}

La presencia de DM generalmente se asocia a engrosamiento de la piel de características diferentes a las de la esclerodermia, principalmente en las extremidades, el cuello y la parte superior de la espalda. Dentro del síndrome de engrosamiento se incluyen tres entidades: a) escleredema diabético; b) piel cérea y movilidad articular limitada; c) empedrado digital2,21.

a) Escleredema diabético $4,6,13,21,28,43-46$. Es un trastorno del tejido conectivo infrecuente, caracterizado por endurecimiento difuso y sin fóvea de la piel que afecta generalmente la porción superior de la espalda, cuello y hombros de pacientes diabéticos. La incidencia es de 2,5 a 3\% de los pacientes diabéticos, observada en ambos tipos de DM, siendo la mayoría de los pacientes obesos y con mal control glucémico. Puede aparecer mayormente entre los 30 y 50 años, más frecuente en el sexo masculino con una relación de 4:1. Se relaciona con obesidad, retinopatía, neuropatía, HTA y cardiopatía isquémica.

De comienzo insidioso y a menudo extensivo, el eritema y el endurecimiento empiezan característicamente en la parte superior de la espalda, aunque también pueden afectar las extremidades, incluidas las manos, lo que podría implicar una limitación del movimiento; es típico que las zonas endurecidas presenten eritema y pápulas sutiles. Los pacientes pueden notar una disminución del tacto suave y dolor en las zonas afectadas (Figura 5). 


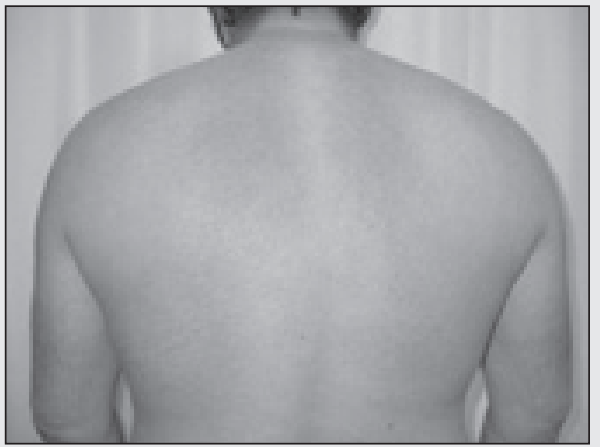

Figura 5: Escleredema diabeticorum. Tomado y adaptado de: Pastor MA, Álvarez P, Mosquera J, Bautista R. Escleredema. Actas Dermofiliofr. 2006; 97(4)287-288.

b) Piel cérea y movilidad articular limita$\mathrm{da}^{13,28,45-51}$. Se caracteriza por un engrosamiento cutáneo esclerodermiforme en el dorso de las manos y antebrazos, asociado a una contractura en flexión de los dedos de las manos, con disminución de la movilidad articular. La incidencia es en promedio del $30 \%$ en pacientes con DM1 y en pacientes con DM2 varía entre un 10 a un $60 \%$; afecta a ambos sexos y se relaciona con larga evolución de la enfermedad y alto riesgo de complicaciones microvasculares.

La piel se torna brillante, no es fácilmente plegable y puede parecer áspera en la superficie extensora de la mano. El proceso comienza en el quinto dedo de la mano y posteriormente se extiende de forma radial hasta afectar las articulaciones interfalángicas, metacarpofalángicas y las articulaciones de mayor tamaño. Para evaluar la movilidad articular limitada se indica al paciente que coloque las manos en posición de rezo, valorándose la contractura en flexión de los dedos de la mano; esto se conoce con el nombre de "signo del rezo positivo" (Figura 6).

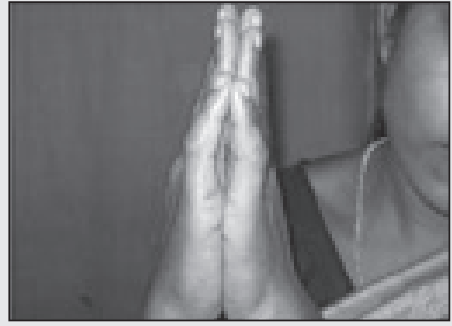

Figura 6: Piel cérea y movilidad articular limitada. Signo del rezo positivo. Tomado y adaptado de: Dependra KT, MohanTD, Agrawal A. Estudio clínico de las dermatosis en diabetes mellitus para establecer sus marcadores. Indian J Dermatol. 2012; 57:287-288.

c) Empedrado digital ${ }^{13,45,52-55}$. Aparece hasta en un $60 \%$ de los pacientes con DM, afecta a ambos tipos de diabetes y puede aparecer en personas no diabéticas hasta en un 20\%; se manifiesta igual en ambos sexos y se presenta en jóvenes y adultos. Puede considerarse un marcador visual de engrosamiento cutáneo o esclerodermiformes de las manos.

Aparecen múltiples lesiones diminutas de aspecto papular (pápulas de Huntley) localizadas en la superficie de extensión y cara lateral de los dedos de las manos, sobre las articulaciones interfalángicas y la zona periungueal.

\section{Piel amarilla ${ }^{21,36,45,56-57}$}

Conocida también como xantosis, anteriormente se consideraba que era consecuencia de niveles elevados de carotinemia ocasionados por una dieta rica en carotenos; posteriormente se demostró que la mayoría de estos pacientes presentaba niveles de carotenemia normales. En la actualidad se le atribuye a un producto formado de la glicosilación no enzimática de color amarillento que se conjuga con el colágeno. Ocurre en aproximadamente el $10 \%$ de los pacientes diabéticos; afecta por igual a ambos sexos y a ambos tipos de DM. Es más frecuente en pacientes con larga evolución de la enfermedad y con mal control metabólico. Aunque no es marcador por excelencia, su presencia orienta al estudio de DM.

La coloración amarillenta ocurre fundamentalmente en aquellas zonas con actividad seborreica, 
como los pliegues nasolabiales y axilares, también en las palmas de las manos y las plantas de los pies. Respeta las escleróticas y tiende a mejorar al compensar los valores de glucemia (Figura 7).

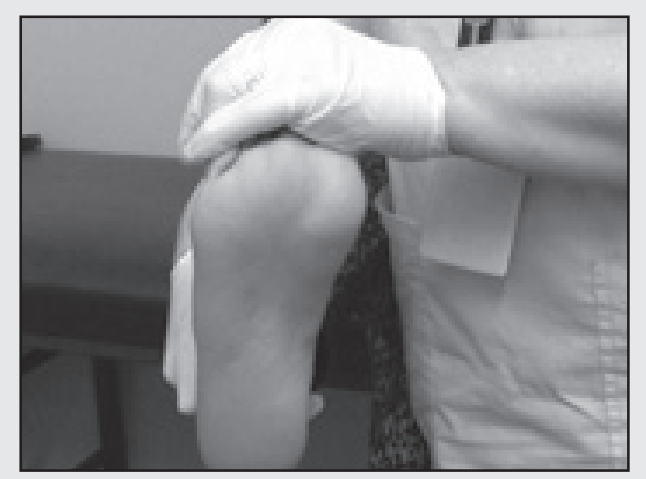

Figura 7: Piel amarilla o xantosis. Imagen propia.

\section{Acantosis nigricans $\mathbf{2}^{21,28,36,55,58-60}$}

Es un marcador cutáneo característico de la resistencia a la insulina y podría constituir el primer signo de DM. Se presenta en un 5\% de la población general y hasta en un $70 \%$ de la población obesa, con alta prevalencia en pacientes con DM2 en donde se presenta hasta en el 30 al $50 \%$ de los pacientes al diagnóstico. Generalmente observada en pacientes adultos aunque ya se empieza a diagnosticar en edades pediátricas acompañando a la obesidad y al síndrome metabólico cada vez mayor en estas edades. Se presenta con una relación de 3:2 en las mujeres.

Se caracteriza por un engrosamiento cutáneo, aterciopelado con hiperpigmentación de color marrón a negro-grisáceo, simétrico, localizado en áreas de flexión como regiones laterales y posteriores del cuello, axilas, pliegues abdominales e ingles, región ano-genital, pliegues submamarios, ombligo, areolas y la zona de los nudillos en las manos. En raras ocasiones se observa en mucosas (Figura 8).

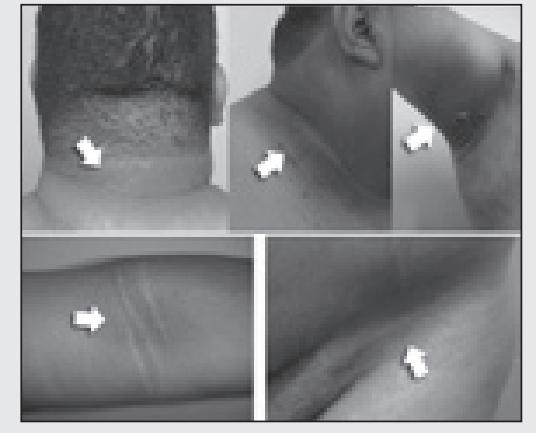

Figura 8: Tomado y adaptado de: www.medicinafamiliarcuenca.com.

\section{Vitiligo $^{13,21,36,61-65}$}

Es un trastorno de la pigmentación adquirido y crónico, con pérdida de la función de los melanocitos epidérmicos de membranas y mucosas y, en algunas ocasiones, de los folículos pilosos. El control de la glucemia no influye en la evolución del vitiligo asociado a la DM. Del 20 al 30\% de los pacientes con vitiligo tiene algún familiar en primer grado con DM. Dawber y col. descubrieron vitiligo en el $4,8 \%$ de los pacientes a quienes se les diagnosticó con DM en la edad adulta en comparación con el 0,7-1\% de la población general. El porcentaje de pacientes con DM 1 y vitiligo oscila alrededor del 1,6\%. En un estudio de 2.000 pacientes con vitiligo se evidenció que el 3,1\% padecía DM.

Se caracteriza por la aparición de máculas blanquecinas, redondas u ovales, con bordes ondulados, rodeadas de piel normal. Miden pocos milímetros hasta varios centímetros y afectan la piel, las mucosas o ambas. Generalmente son asintomáticas, pero pueden presentar prurito o sensación urente en el sitio que precede o acompaña la lesión; de curso lento y progresivo, con remisiones y exacerbaciones que pueden correlacionarse con algunos factores desencadenantes. Las lesiones tienen predilección por áreas como la cara, la ingle, la axila, la areola y los genitales; afectan también tobillos, codos, rodillas, cuero cabelludo y otras zonas que puedan estar expuestas a traumas a repetición (Figura 9). 


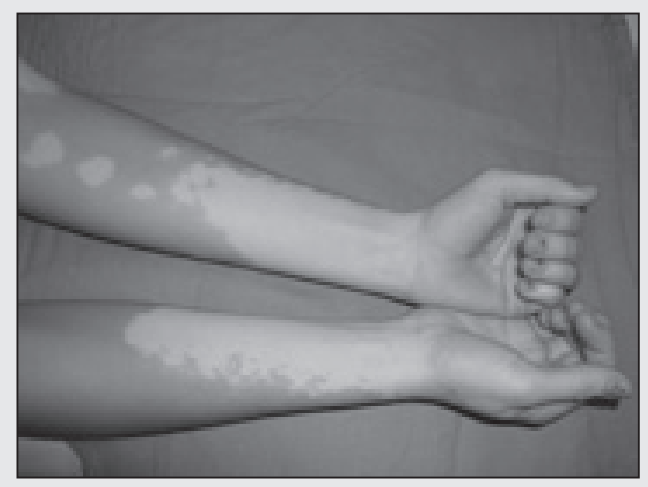

Figura 9: Vitiligo. Tomado y adaptado de: www.segiovano.blogspot.com.

\section{Liquen plano ${ }^{13,24,66-71}$}

Es una patología inflamatoria de la piel y las mucosas, de origen desconocido y patogenia autoinmunitaria, de curso crónico, autolimitado que se resuelve en un período de meses a años. Se ha reportado en la literatura la asociación entre alteración de la prueba de tolerancia oral a la glucosa, diabetes y liquen plano (LP), especialmente el LP oral. El LP se puede presentar en 1,6 al 5,6\% de la población diabética, más comúnmente en pacientes con DM1; asimismo se ha observado que la DM se ha encontrado en el 1 al $37 \%$ de los pacientes con LP oral y han hallado en pacientes con LP oral historia familiar de DM hasta en un 30\%. Un estudio de la Universidad de Santiago de Compostela (España) halló en una serie de pacientes con LP oral asociado a $27,4 \%$ a DM2 y el $17,7 \%$ asociado con alteración de la prueba de tolerancia oral a la glucosa.

Las lesiones típicas del LP consisten en pápulas poligonales y pruriginosas, de coloración violácea y con una superficie brillante surcada por una estriación blanquecina (estrías de Wickham). Estas pápulas muestran una distribución simétrica y se localizan preferentemente en la cara anterior de las muñecas y tobillos, y muy frecuentemente con afectación de la mucosa bucal y en un cuarto de los pacientes con LP puede ser la única manifestación de la enfermedad (Figura 10).

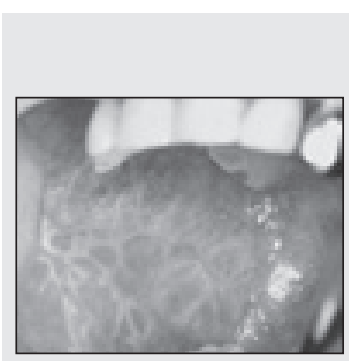

A

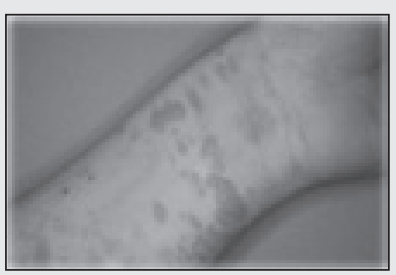

B
Figura 10: Liquen Plano (LP). Tomado y adaptado de: www.uv.es y www.medeho.com. A) LP oral; B) LP anular.

\section{Xantomas eruptivos ${ }^{13,21,24,73-76}$}

El término xantoma designa a un grupo de enfermedades dermatológicas cuyo sustrato anatomopatológico es el acúmulo de lípidos en plasma. Los xantomas eruptivos se caracterizan por un aumento de VLDL-colesterol, triglicéridos y quilomicrones y se relacionan con el déficit o la insulinorresistencia, conllevando a la disminución de la actividad de la enzima lipoproteína lipasa que provoca una elevación de las concentraciones séricas de triglicéridos. Se forman cuando las concentraciones séricas de triglicéridos aumentan por encima de 1.000 a $3.000 \mathrm{mg} / \mathrm{dl}$. La incidencia de XE en DM se estima en $0,1 \%$. Se puede observar en DM1 y DM2, con mal control metabólico.

Los XE son lesiones de aspecto papular, rosado-amarillentas o amarillo-anaranjadas entre 1-4 $\mathrm{mm}$ de diámetro, firmes, múltiples y cada una con un halo eritematoso. Aparecen de forma súbita en las superficies extensoras y en ocasiones son pruriginosas; se localizan predominantemente en rodillas, codos, regiones glúteas y tronco (Figura 11).

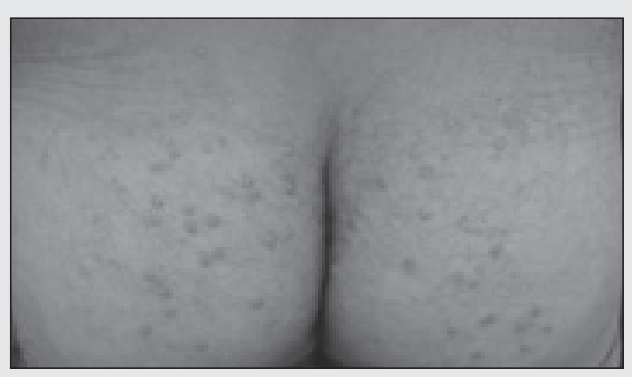

Figura 11: Xantomas eruptivos. Tomado y adaptado de: www.piel-l.org. 


\section{Alopecia areata ${ }^{77-82}$}

El término alopecia areata (AA) se define como la disminución o pérdida del pelo localizada, generalizada, temporal o definitiva de cualquier tipo $u$ origen. La AA es una alopecia no cicatrizal, recurrente, de origen autoinmune e inflamatorio, con una aparente base genética. La asociación entre la AA y la DM1 es compleja. Los autores han encontrado que existe mayor riesgo para desarrollar DM en miembros de familia de pacientes con AA. Se postula que varios locis de riesgo en los pacientes con AA son comunes con los de DM1. La incidencia de DM1 en pacientes con AA oscila ente el 0,4 al $4 \%$, según diversas series.

La AA puede afectar cualquier área pilosa pero se asienta en un $90 \%$ de los casos en el cuero cabelludo. La clásica lesión de AA es un área bien demarcada de pérdida de pelo, de foma oval o redondeada, la cual puede ser aislada o múltiple sobre una piel normal, con preservación de los orificios foliculares sin cicatrización. Las placas alopécicas son habitualmente asintomáticas aunque algunos pacientes refieren sensación de prurito, dolor o ardor (Figura 12).

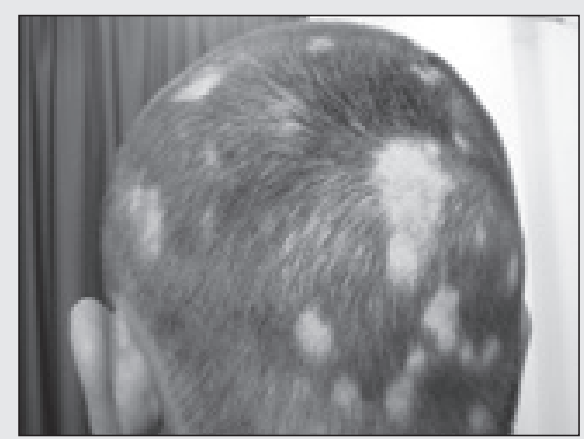

Figura 12: Alopecia areata. Tomado y adaptado de: www.uphairs.com.

\section{Siringoma de células claras $^{21,83-87}$}

Los siringomas son neoplasias benignas de las glándulas sudoríparas ecrinas. Una curiosa e infrecuente variante se denomina siringoma de células claras (SCC), implicada casi exclusivamente con la DM. Es poco frecuente, aparece cerca de los 50 años y mayoritariamente en mujeres. La frecuente asociación entre DM y SCC no está totalmente explicada y ha sido poco reportada en la literatura.

Los SCC clínicamente son similares a los sirin- gomas comunes. Se presentan como pequeñas pápulas (1 a $5 \mathrm{~mm}$ ) generalmente múltiples, de consistencia firme y del color de la piel, a veces con un tono amarillento; su distribución puede seguir un patrón lineal y pueden localizarse de forma simétrica preferentemente en párpados (borde libre inferior) y mejillas (Figura 13).

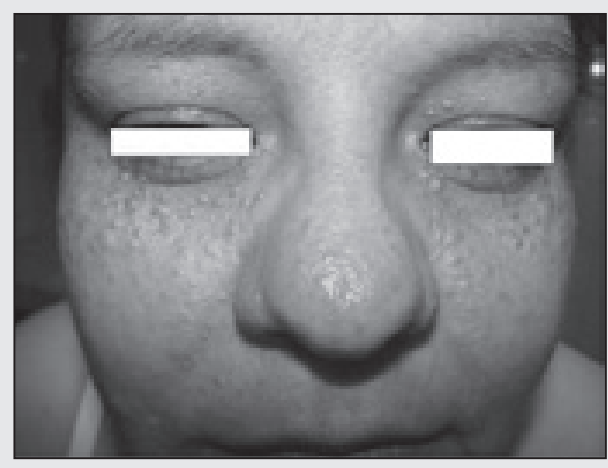

Figura 13: Siringoma de células claras. Tomado y adaptado de: www.piel-I.org.

\section{Psoriasis ${ }^{13,88-90}$}

Enfermedad de carácter inflamatorio, crónica, multifactorial, determinada genéticamente, de gran heterogeneidad clínica. Relacionada con la DM, aunque no existe una explicación clara y precisa que justifique la asociación, se ha encontrado una incidencia de hasta un $27 \%$ en los pacientes con psoriasis y hasta un $24 \%$ refiere historia familiar de DM. Clínicamente caracterizada por una placa eritematosa, de bordes definidos y superficie irregular descamativa, que al realizar el raspado de la lesión deja una superficie eritematosa con pequeños puntos sangrantes (rocío hemorrágico de Auspitz). Su disposición es simétrica y bilateral en las superficies extensoras. El prurito puede o no estar presente en las lesiones y su intensidad es variable, siendo más intenso en los brotes agudos, en la localización del cuero cabelludo y en la zona anogenita (Figura 14). 


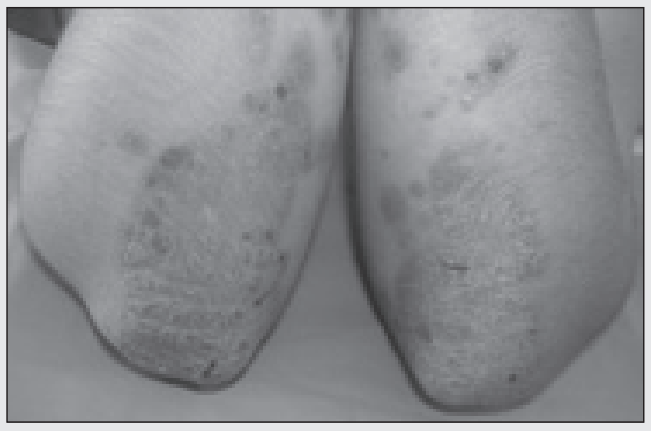

Figura 14: Psoriasis. Tomado y adaptado de: www.doctorrenie.wordpress.com.

\section{DERMATOSIS RELACIONADAS CON UN ORIGEN INFECCIOSO}

Clásicamente se ha considerado a los pacientes con DM con mayor susceptibilidad a las infecciones en general, con aumento de las complicaciones e incluso con mayor mortalidad comparados con la población general. Estudios posteriores demostraron que el aumento en la mortalidad debe atribuirse en gran medida a las complicaciones de los trastornos cardiovasculares preexistentes y no a la infección no controlada. Lo que aún se postula es que los pacientes con mal control glucémico presentan una incidencia mayor de infecciones cutáneas que oscila entre el 20 y el $50 \%$; éstas pueden tener mayor gravedad y ser resistentes al tratamiento, con mayor tendencia a las recidivas comparadas con la población general. Las causas de esta postulación no sólo radican en la hiperglucemia sostenida, sino que existen otros factores predisponentes, como la alteración en la función de los leucocitos polimorfonucleares por disminución de la movilización y quimiotaxis, reducción de la fagocitosis (más evidente cuando la glucemia es mayor a $250 \mathrm{mg} / \mathrm{dl}$ ), disminución de la adherencia y la actividad bactericida, alteraciones en la función de los monocitos con disminución de la cifra total circulante, y en la inmunidad celular principalmente con defecto en la producción de interleuquina 2 y disminución de la capacidad mitogénica de los linfocitos $T$.

Las alteraciones en la microcirculación de los pacientes con DM pueden provocar hipoxia y menor perfusión al tejido. Se consideran también las alteraciones propias que se pueden encontrar en la piel del paciente con DM: mayor predisposición por la rotura de la piel, aumento en la descamación, incremento en la queratinización y propensión a la pérdida del $\mathrm{PH}$ ácido cutáneo (por alteración en la producción de glándulas exocrinas sudoríparas y sebáceas). Las infecciones cutáneas pueden presentarse como lesiones precursoras de la DM y cuando se manifiestan en sujetos no diabéticos se debe sospechar y pesquisar. Las infecciones cutáneas más relacionadas en los pacientes diabéticos son de causa micótica y bacteriana ${ }^{13,17,21,91-99}$.

\section{Infecciones micóticas}

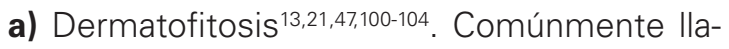
madas tiñas, son un conjunto de micosis superficiales que afecta la piel, uñas y pelos. En relación con la diabetes, las infecciones por dermatofitos no son más frecuentes que en la población general, sin embargo la dermatofitosis del pie es más prevalente en las personas diabéticas que en la población general. Su importancia radica en que la tiña puede crear fisuras y puertas de entrada que propician infecciones bacterianas potencialmente graves en pacientes con DM.

La tiña pedis que se vincula con mayor prevalencia en la DM, se caracteriza por espacios interdigitales muy pruriginosos que muestran un aspecto escamoso, eritematoso y macerado. Puede haber vesículas y pústulas. Otra variante de la tiña del pie es una distribución en "mocasín" que se extiende desde la planta del pie hasta la cara lateral. La tiña del pie puede afectar las uñas, que pueden mostrar un cuerpo grueso, áspero y de color amarillento (Figura 15).

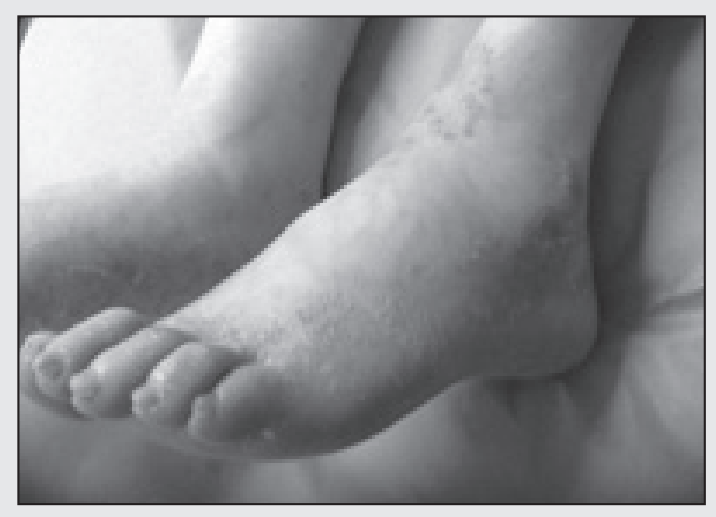

Figura 15: Tiña pedis (variante de distribución en mocasín). Imagen propia. 
b) Candidiasis 7,13,17,21,56,105. Lesión fúngica oportunista causada por cualquier especie de levaduras del género Candida, de la cual la más común es la Cándida albicans. Las infecciones candidiásicas de las mucosas, los genitales, los pliegues cutáneos y las uñas son más prevalentes en los pacientes con DM mal controlada con respecto a la población general, presentándose mayormente en mujeres. Aunque las infecciones por candidiasis pueden ser la presentación inicial de la diabetes, generalmente afectan a pacientes que ya han sido diagnosticados y traduce mal control de la enfermedad.

Las formas clínicas más frecuentes en el diabético incluyen (Figura 16): a) candidiasis de la mucosa bucal; b) paroniquia candidiásica; c) vulvovaginitis candidiásica; d) balanitis candidiásica; e) intertrigo candidiásico.

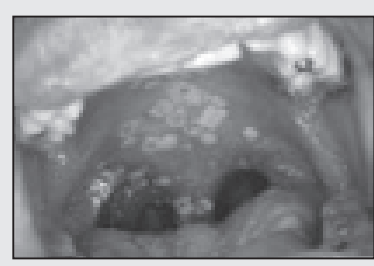

A

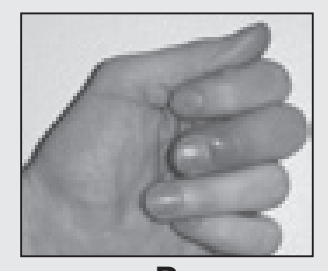

B

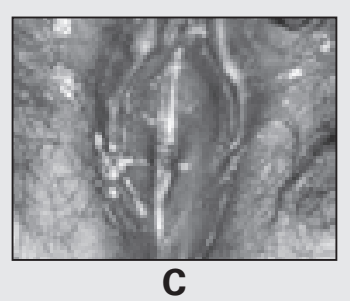

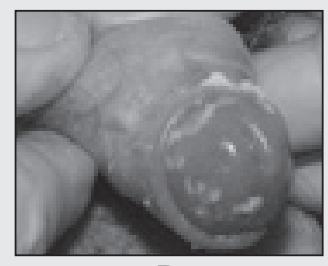

D

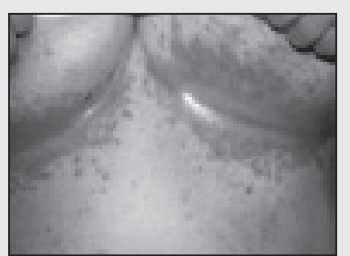

$\mathbf{E}$
Figura 16: Candidiasis. Tomado y adaptado de: www.udl.es www. Piel-l.org www. adolfoneda.com. A) Candidiasis bucal; B) paroniquia candidiásica; C) vulvovaginitis candidiásica; D) balanitis candidiásica; E) intertrigo candidiásico.

c) Mucormicosis rinocerebral ${ }^{17,105-108}$. La mucormicosis es una infección oportunista producida por los hongos del grupo Mucorales, miembros de la clase de los cigomicetos. La mucormicosis rinocerebral (MR) es la forma clínica más relacionada con DM, sobre todo en casos de cetoacidosis diabética.

La MR suele presentar un curso rápido y potencialmente fatal. A menudo los síntomas iniciales son inespecíficos con cefalea, fiebre y letargia; es característica la presencia de un material costroso negro (que le da un aspecto de placa necrótica) o purulento en los cornetes nasales, tabique, paladar o en la piel adyacente.

\section{Infecciones bacterianas}

a) Piodermitis ${ }^{21,109-110}$. Proceso inflamatorio infeccioso en la piel originado por bacterias gram positivas piógenas principalmente Estafilococo aureus y Estreptococo pyogenes beta hemolítico, caracterizado por producción de lesiones purulentas. No se discute que los pacientes con mal control glucémico al presentarse, éstas sean más crónicas, rebeldes al tratamiento, más recidivantes y de localizarse en miembros inferiores con mayor probabilidad de desarrollo de úlceras infecciosas que pueden progresar rápidamente a gangrena y aumentar el riesgo de amputación.

Las piodermitis más frecuentemente asociadas a pacientes con DM son: impétigo, ectima, erisipela, celulitis, foliculitis, forunculosis, ántrax o carbunco (Figura 17).

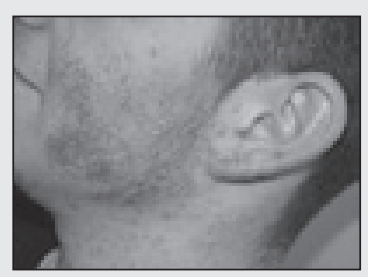

A

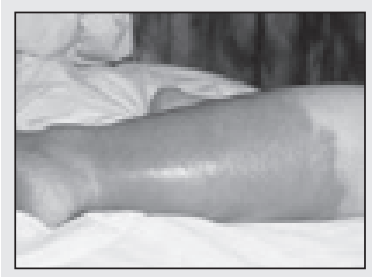

C

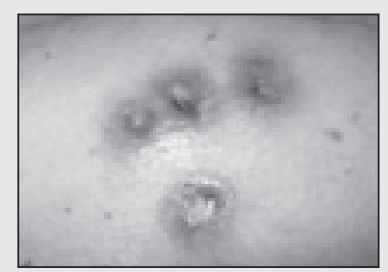

B

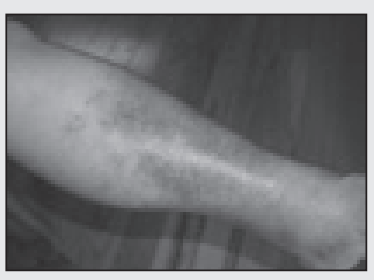

D 


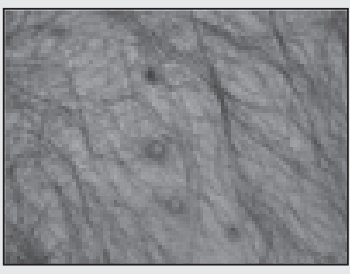

E

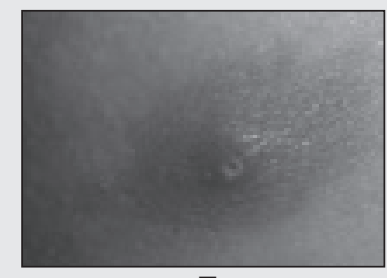

$\mathbf{F}$

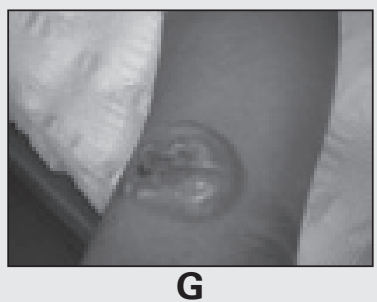

Figura 17: Piodermitis. Tomado y adaptado de: www. docconde.com www.dermatoweb2.udl.es. A) Impétigo; B) ectima; C) erisipela; D) celulitis; E) foliculitis; F) forunculosis; G) ántrax o carbunco.

b) Eritrasma21,56,111-115. Infección bacteriana superficial de la piel causada por Corynebacterium minutissimun (bacilo gram positivo). Las pacientes obesas y diabéticas con más susceptibles. Su frecuencia puede ser de 58\% contra $43 \%$ en la población general. Se ha encontrado una incidencia de DM del 20 al 50\% en pacientes con diagnóstico de eritrasma.

Localizada principalmente en zonas intertriginosas de grandes pliegues (axilar, inguinal, submamario) y áreas interdigitales de pies, se caracteriza por la formación de placas de aproximadamente $10 \mathrm{~cm}$, de color marrón rojizo, forma irregular y bien delimitadas. Al inicio tiene una superficie suave, cubierta por escamas finas y luego tiende a descamarse y tornarse rugosa. Normalmente no se disemina y su curso es crónico, sin tendencia a la remisión y es asintomática o puede producir escaso prurito (Figura 18).

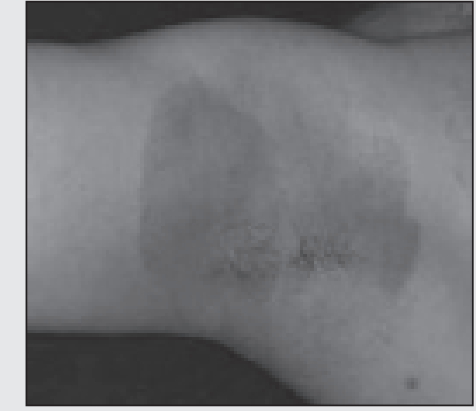

Figura 18: Eritrasma. Tomado y adaptado de: www.eritrasma.com

c) Infección necrotizante de tejidos blandos. Estas infecciones graves de tejidos blandos pueden afectar a huéspedes previamente sanos en pacientes con DM; este tipo de infecciones suele ser más frecuente y tiene una evolución mucho más complicada que la población general. Las dos infecciones necrotizantes vinculadas a DM son la fascitis necrotizante y la gangrena de Fournier.

- Fascitis necrotizante ${ }^{116-119}$. Infección rápida y progresiva de la piel y de los tejidos blandos, asociada a destrucción y necrosis de la fascia y de la grasa, con o sin celulitis, acompañada de toxicidad sistémica y alta mortalidad. Puede ser polimicrobiana incluyendo por lo menos un germen anaerobio (Bacteroides, Clostridium, Peptoestreptococos), uno o más anaerobios facultativos (Estreptococo no A) y enterobacterias o monomicrobiana, fundamentalmente por Estreptococo beta hemolítico del grupo A, a veces en combinación con Estafilococo aureus. Diversos estudios han reportado que del 20 al $80 \%$ de los pacientes con fascitis necrotizante tenía diagnóstico de DM (Figura 19).

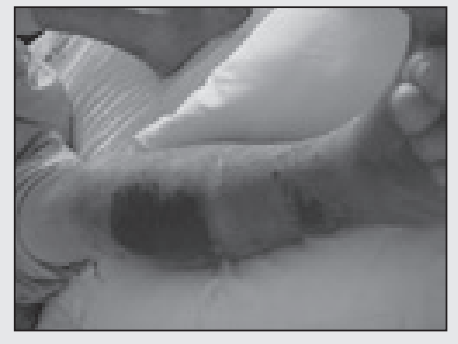

Figura 19: Fascitis necrotizante. Tomado y adaptado de: www.piel-l.org. 
- Gangrena de Fournier ${ }^{13,120-122}$. Es una subclasificación anatómica de la fascitis necrotizante; es una infección de la región perineal, perianal, genital y del tercio inferior del abdomen, que compromete de manera fulminante y progresiva la vida del paciente. La incidencia de DM en los pacientes con GF oscila entre el 40 al $66 \%$ y la mortalidad es tres veces más elevada comparada con los pacientes no diabéticos. Es polimicrobiana, aislándose de tres a cinco gérmenes; los más frecuentes son aerobios gram negativos (Escherichia coli y Pseudomona aeruginosa), aerobios gram positivos (Estafilococos aureus y epidermidis) y anaerobios (Clostridium difficile y Bacteroides fragilis) (Figura 20).

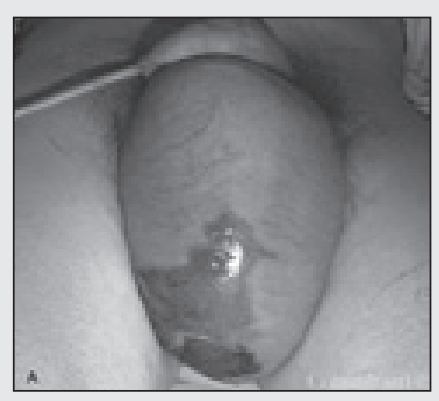

Figura 20: Gangrena de Fournier. Tomado y adaptado de: www.consultantlive.com.

d) Otitis externa maligna. Es una infección generalmente bacteriana, necrotizante rara y grave, que se produce en el conducto auditivo externo. De los pacientes con este diagnóstico, hasta un 90\% es diabético y de edad avanzada. Producida por gérmenes oportunistas, siendo Pseudomona aeruginosa el más frecuentemente relacionado, aunque también se ha asociado a Estafilococo aureus o epidermidis, Proteus mirabilis, Aspergilus y Candida (Figura 21).

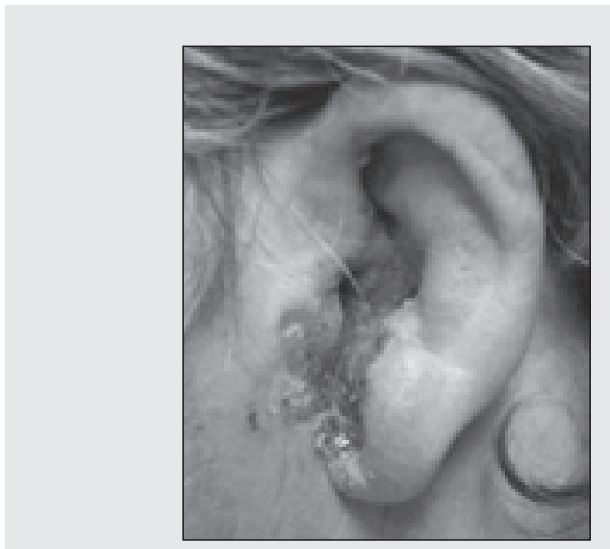

Figura 21: Otitis externa maligna. Tomado y adoptado de: www.wikipedia.org.

\section{DERMATOSIS RELACIONADAS CON LAS COMPLICACIONES DE LA DIABETES MELLITUS}

\section{Neuropatía periférica diabética (NPD) (,7,17,123 $^{4}$}

Es la complicación de mayor prevalencia secundaria a DM; puede deberse a una alteración en las fibras sensoriales, motoras o autonómicas, suele ser bilateral y afectar mayormente a las extremidades inferiores.

En la NPD autonómica se dañan las fibras simpáticas, con inactivación de las glándulas sudoríparas que produce sequedad de la piel. La NPD motora conlleva a un desequilibrio entre los músculos flexores y extensores, desplazamiento de los cojinetes del tejido y subluxación de los huesos del pie (Figura 22).

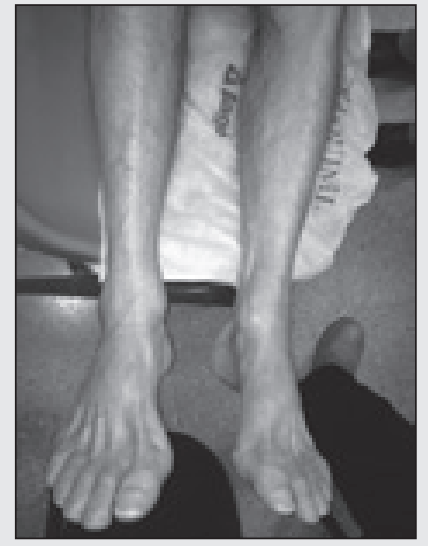

Figura 22: Pie neuropático. Imagen propia. 


\section{Macroangiopatía diabética ${ }^{13,21}$}

En las extremidades inferiores de los pacientes con enfermedad arterial periférica, la piel se encuentra brillante, fina, lisa, fría, pálida, con pérdida parcial o total de pelo, atrofia de la grasa subcutánea, alteración en la palpación de pulsos, cianosis con la elevación del miembro, rubor postural, retraso del llenado capilar y onicodistrofias.

\section{Microangiopatía diabética ${ }^{13,21,36,66}$}

La microangiopatía diabética (Figura 23) está involucrada en el desarrollo de manifestaciones cutáneas como:

- Dermopatía diabética (descrita anteriormente).

- Púrpura pigmentada: caracterizada por múltiples máculas pequeñas, que se unen para formar parches de color rojo-naranja, localizándose en tobillos y dorso de los pies.

- Piel roja y rubeosis facial: las mujeres jóvenes descompensadas son las más afectadas; clínicamente se observa una coloración rojiza en la piel.

- Eritema símil erisipela: hay enrojecimiento de la piel en los miembros inferiores, sin signos clínicos ni de laboratorio de infección.

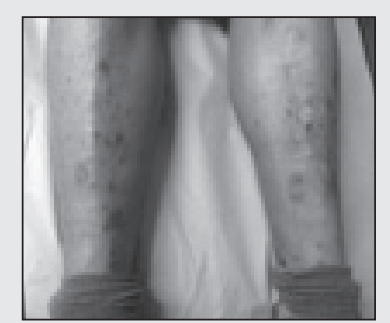

A

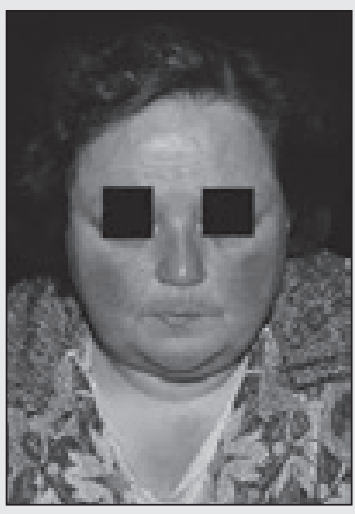

C

Figura 23: Microangiopatía diabética. A) Dermopatía diabética; B) púrpura pigmentada (imagen propia); C) rubeosis facial (www.salerno.uni. muenster.de).

\section{Pie diabético ${ }^{124-126}$}

Según la Organización Mundial de la Salud (OMS), se define como la infección, ulceración y/o destrucción de tejidos profundos, asociada a neuropatía y a diferentes grados de enfermedad vascular periférica e inducida por la hiperglucemia sostenida en miembros inferiores de pacientes con DM. El espectro clínico del pie diabético comprende (Figura 24):

- Mal perforante plantar: conocido también como úlcera neuropática, localizada en los puntos de mayor presión y traumatismo a repetición (dedos de los pies, talones, cabezas de metatarsianos).

- Neuroartropatía de Charcot: artropatía neuropática relativamente dolorosa, progresiva, degenerativa, de una o múltiples articulaciones, causada por un déficit neurológico subyacente.

- Gangrena: hay muerte del tejido a consecuencia de la pérdida del suministro de sangre; puede ser seca (obstrucción del flujo sanguíneo) o húmeda (secundaria a infección que produce inflamación que interfiere en la circulación sanguínea).

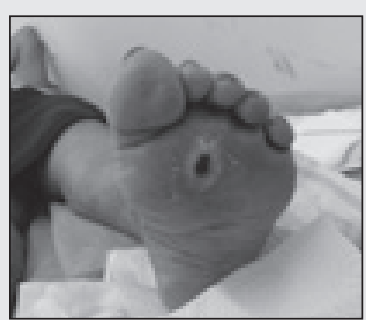

A

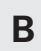

B

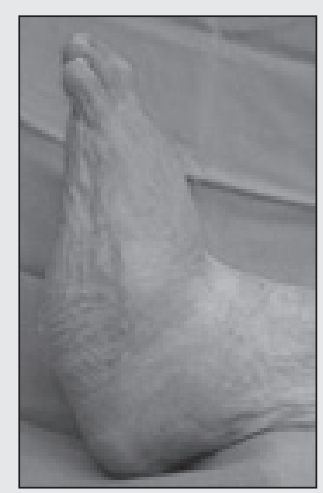

B

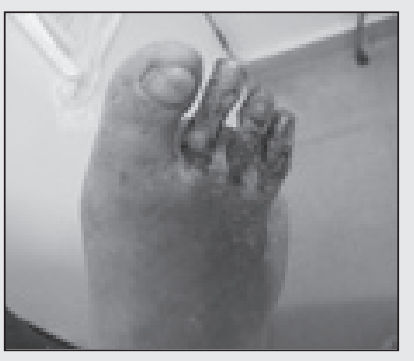

C

Figura 24: A) Mal perforante plantar (imagen propia); B) neuroartropatía de Charcot (www.estudiabetes.org); C) gangrena (imagen tomada del Ateneo Bibliográfico de Pie Diabético. Escuela de Graduados SAD 2013). 


\section{DERMATOSIS RELACIONADAS CON ELTRATAMIENTO DE LA DIABETES}

\section{Inducidas por insulina ${ }^{13,17,21,66,128}$}

Las reacciones cutáneas inducidas por el uso de insulina han disminuido considerablemente desde la introducción de la insulina humana recombinante y los análogos de insulina los cuales son altamente purificados. Las manifestaciones cutáneas que se observan con la administración de insulina consisten en: reacciones alérgicas, lipodistrofia y menos frecuentemente, formación de abscesos.

- Reacciones alérgicas. Los pacientes que se administran insulina, virtualmente desarrollarán anticuerpos contra ésta. Su aparición dependerá de: a) especie de insulina, su fuente y pureza; b) forma farmacéutica; c) tipo de tratamiento insulínico (la terapia discontinua favorece la respuesta inmunológica); d) secreción endógena de insulina (pacientes que preservan cierta capacidad de secretar insulina tienen menor respuesta inmunológica).

La reacción alérgica a la insulina puede ser:

- Local: caracterizada por ardor, prurito, eritema y dolor inmediato a la aplicación de la insulina, encontrándose nódulos subdérmicos de tamaño variable en el sitio de inoculación; en ocasiones se puede observar edema.

- Generalizada: caracterizada por eritema o urticaria generalizados, intenso prurito, pudiendo o no acompañarse de angioedema, edema de glotis, broncoespasmo y shock anafiláctico. Producida por la interacción de la lgE contra la insulina.

- Lipodistrofia. Consiste en la pérdida (lipoatrofia) o aumento (lipohipertrofia) del tejido celular subcutáneo en el sitio de la administración de insulina. La lipoatrofia se observa más en niños y en mujeres obesas, mientras que la lipohipertrofia se observa mayormente en el sexo masculino; su aparición con el uso de insulinas humanas recombinantes y análogos es muy rara.

La lipoatrofia (Figura 25) aparece alrededor de los 6 a 24 meses después del inicio del tratamiento insulínico. Se caracteriza por placas deprimidas, delimitadas, de diferente tamaño, pudiendo tener alteraciones de la sensibilidad. Por su parte, la lipohipertrofia (Figura 26) se caracteriza por nódulos de tamaño variado que se extienden sobre planos profundos con algún grado de alteración de la sensibilidad.

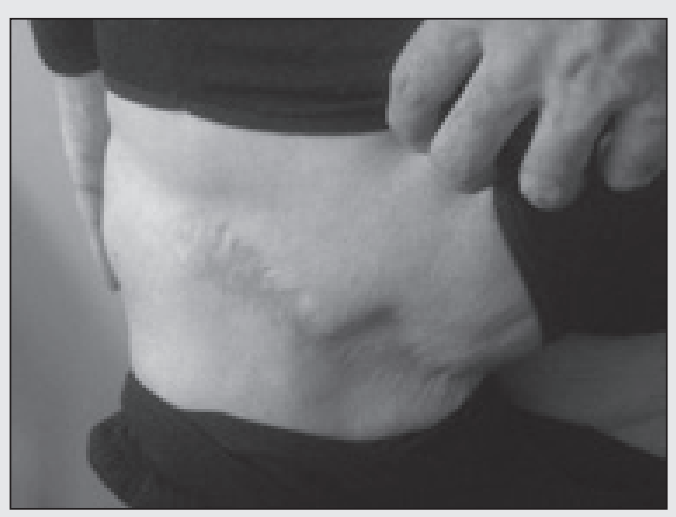

Figura 25: Lipoatrofia. Imagen propia.

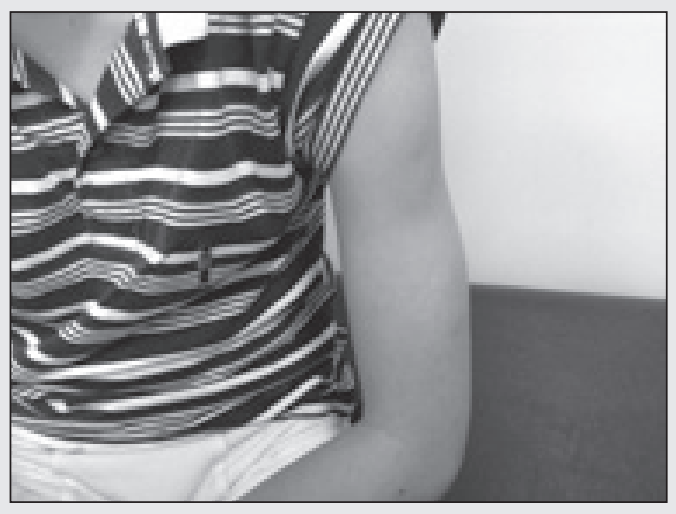

Figura 26: Lipohipertrofia. Imagen propia.

\section{Inducida por antidiabéticos orales ${ }^{13,17,21,129-130}$}

- Sulfonilureas. La mayoría de las reacciones cutáneas ha sido reportada con el uso de las sulfonilureas, principalmente las de primera generación (tolbutamida y clorpropamida). La lesión cutánea más comúnmente observada con su uso es la erupción maculopapular (Figura 27); también se puede notar prurito persistente o intermitente, lesiones por eritema generalizado, urticaria, reacción de fotosensibilidad, erupción liquenoide, eritema multiforme, dermatitis exfoliativa, síndrome de Stevens-Johnson, eritema nodoso y necrolisis epidérmica tóxica (síndrome de Lyell). Con el uso de las sulfonilureas de segunda generación (glibenclamida, glipizida y glimepirida) también se han observado reacciones cutáneas como eritema, exantema, fotosensibilidad, prurito y urticaria.

- Otros agentes antidiabéticos orales. Reaccio- 
nes similares a las observadas con sulfonilureas de segunda generación se han reportado con el uso de metformina pero con menor frecuencia. Asimismo hay reporte de la aparición de eritema multiforme después de dos semanas de tratamiento con acarbosa.

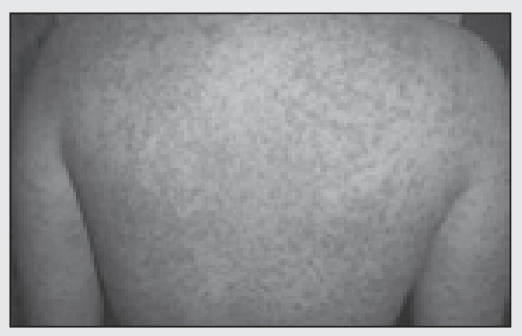

Figura 27: Erupción maculopapular. Tomado y adaptado: www.piel-I.org.

\section{CONCLUSIONES}

Cerca de un 30 a un $70 \%$ de las personas con DM presentará lesiones cutáneas en el transcurso de la enfermedad.

El conocimiento de las manifestaciones dermatológicas asociadas a DM puede favorecer un diagnóstico temprano y un mejor control de la enfermedad.

Queda demostrado que la realización de una historia clínica detallada y un examen físico completo pueden orientar al diagnóstico de DM incluso antes de tener manifestaciones sistémicas floridas. Asimismo el hallazgo de signos clínicos cutáneos puede revelar la presencia de complicaciones crónicas neuropáticas y/o angiopáticas.

Al igual que con otras especialidades, el médico diabetólogo debe trabajar en equipo con el dermatólogo y viceversa, para la atención integral y oportuna de estos pacientes.

\section{REFERENCIAS}

1. Wahiz Z, Kanjee A. Cutaneous manifestations of diabetes meIlitus. J. Pak. Med. Assoc. 1998; 48:304-305.

2. MahmoodT, Bari A, Agha H. Cutaneous manifestations of diabetes mellitus. J Pak. Assoc. Dermatol. 2005; 15:227-232.

3. Oumeish OY. Skin disorders in patient with diabetes. Clin. Dermatol. 2008; 26:235-242.

4. Santamaría GV, Barrios E. Manifestaciones cutáneas de la diabetes mellitus. Rev. Cent. Dermatol. Pascua 2001; 10(1)45-56.

5. Halprin KM, Ohkawara A. Glucose entry into the human epidermis, I: the concentration of glucose in the human epidermis. J Invest. Dermatol. 1967; 49:559-560.
6. Yosipovitch G, Hodak E, Vardi P, et al. The prevalence of cutaneous manifestations in IDDM patients and their association with diabetes risk factors and microvascular complications in type 2 diabetes. Diabetes Care 1999; 22:1745.

7. Pérez Ml, Kohn SR. Cutaneous manifestations of diabetes meIlitus. J. Am. Acad. Dermatol. 1994; 30:519-531.

8. Rodríguez E. Manifestaciones cutáneas de la diabetes mellitus. Univ. Med. 2003; 44:179-187.

9. Romano G, Morreti G, Di Benedetto. Skin lesions in diabetes mellitus: prevalence and clinical correlations. Diabetes Res. Clin. Pract. 1998; 39:101- 06.

10. Saenz ML. Manifestaciones cutáneas de las enfermedades sistémicas. Rev. Med. Clin. Condes 2011; 22(6)749-756.

11. Guerra MM, Fernández M, Soler SF, Uribe-Echeverría Al, Rodríguez GA. Estudio de las enfermedades dermatológicas en diabéticos del Centro de Atención al Diabético (CAD) de la provincia de Matanzas, Cub. Año 2003. Rev. Med. Electro. 2008; 30(1).

12. Kahn CR. Insulin action, diabetogenes and the cause of type II diabetes mellitus. Diabetes 1994; 43:1066-1084.

13. Cabo H. Manifestaciones cutáneas de la diabetes mellitus. $1^{\circ}$ Ed. Héctor A. Macci, Buenos Aires, 1996.

14. Brownlee $M$, Vlassara $H$, Kooney $A$ et al. Aminoguanidine prevent diabetes-induced arterial wall protein crosslinking. Science 1986; 232:1629-1632.

15. Delbridge L, Ellis CS, Robertson K et al. Non enzymatic glycosylation of keratin from stratum corneum of the diabetic foot. BR J Dermatol 1985; 112:547-554.

16. Ngo B, Hayes K, DiMiao D, Srinivasan S, Huerter C, Rendell M. Manifestations of cutaneous diabetic microangiopathy. Am. J. Clin. Dermatol. 2005; 6(4):225-237.

17. Zaballos D, Garrido Calvo A, Cía Blasco P, Esteve Lafuente E, Pinós Laborda P. Manifestaciones cutáneas de la diabetes. Rev. Interconsulta, 2001; 15(8):43-50.

18. Farías M, Kolbach R. Serrano V, Hasson N. Diabetes Mellitus y piel: lesiones cutáneas y su significado clínico. Rev. Chil. Endocrinol. Diabetes 2011; 4(1)26-31.

19. Páez E. Piel y diabetes mellitus. Dermatología. Venez. 1999; 31(1):40-46.

20. Ferringer T, Miller OF. Cutaneous manifestation of diabetes meIlitus. Dermatol. Clin. 2002; 20:483-492.

21. Mark H, Lowitt J y Dover S. Manifestaciones cutáneas de la diabetes mellitus. En Kahn R. y colaboradores. Joslin's Diabetes Mellitus. $14^{\circ}$ Ed. Barcelona, España: Lippincott Williams \& WiIkins 2007; 62:1049-1060.

22. Vahora R, Thakkar S, MarfatiaY. Skin, a mirror reflecting diabetes mellitus. A longitudinal study in a tertiary care hospital in Gujart. Indian. J. Endocr. Metab. 2013; 17(4):659-664.

23. YosipovitchG, Hodak $E$, Vardi $P$, et al. The prevalence of cutaneous manifestations in IDDM patients and their association with diabetes risk factors and microvascular complications in type 2 diabetes. Diabetes Care, 1999; 22:1745.

24. Freinkel RK. Manifestaciones cutáneas de las enfermedades endocrinas. En: FitzpatrickTB. Dermatología en Medicina General. $5^{\circ}$ Ed. Buenos Aires: Médica Panamericana; 2002; 2199-2217.

25. Sibbald RG, Landolt SJ, Toth D. Skin and diabetes. Endocrinol. Metab. Clin. North Am. 1996; 25(2):463-472.

26. Morgan A, Schwartz R. Diabetic dermopathy: a subtle sign with grave implications. J. Am. Acad. Dermatol. 2008; 58:447-451.

27. Parra C, Guarda R. La piel en trastornos sistémicos comunes. En: Guarda R. Gubelin W, Ed. Dermatología Esencial. Editorial Mediterráneo 2010; 251-252.

28. Zaballos D, Garrido Calvo A, Cía Blasco P, Esteve Lafuente E, Pinós Laborda P. Manifestaciones cutáneas de la diabetes. Rev Interconsulta. 2001; 15(8):43-50.

29. Reid S, Ladizinski B, Lee K, Baibergenova A, Alavi A. Update on necrobiosis lipoidica: $A$ review of etiology, diagnosis and treatment option. J. Am. Acad. Dermatol. 2013;34:5 (abst). 
30. Muller SA, Winkelmann RK. Necrobiosis lipoidica diabeticorum: a clinical and pathological investigation of 171 cases. Arch. Dermatol. 1966; 93:272- 281.

31. Paron NG, Lamber PW. Cutaneous manifestations of diabetes mellitus. Prim. Care 2000; 27:371-383.

32. O'Toole EA, Kennedy U, Nolan JJ, et al. Necrobiosis lipoidica: only a minority of patients have diabetes mellitus. Br. J. Dermatol. 1999; 140:283-286.

33. Verrotti A. Chiarelli F, Amerio P, et al. Necrobiosis lipoidica diabeticorum in children and adolescents: a clue for underlying renal and retinal disease. Pediatr. Dermat. 1995:12:220-223.

34. Feel C, Aragües M. Necrobiosis lipoidea. Piel 1999; 14: 295-302.

35. Derrighetti M, Hohl D, Krayenbuhl BH, et al. Bullosus diabeticorum in a newly discovered type 2 diabetes mellitus. Dermatology 2000; 200:366.367.

36. López S, Becerril F. Manifestaciones cutáneas de la diabetes mellitus, una manera clínica de identificar la enfermedad. Rev. Endocrinol. Nut. 2005; 13(2):75-87.

37. Jabbour S, et al. Endocrinopathies and the skin. Int. J Dermatol. 2000; 39:88-99.

38. Lipsky BA, Baker PD, Ahroni JH. Diabetic bullae: 12 cases of a purportedly rare cutaneous disorder. Int. J. Dermatol. 2000; 39:196-200.

39. Nebesio C, Lewis C, Chuang T. Lack of an association between granuloma annulare and type 2 diabetes mellitus. Br. J. Dermatol. 2002; 146:122-124.

40. Choudry K, Charles-Holmes R. Are patients with localized nodular granuloma annulare more likely to have diabetes mellitus? Clin. Exp. Dermatol. 2000; 25:451-452.

41. Fleming $C$, Michelena MA, Garritano MV y col. Haga su diagnóstico. Placas eritematosas en tronco. Granuloma anular generalizado. Arch. Argent. Dermatol. 2011; 61(1):30-33.

42. Corigliano M, Achembach RE. Granuloma anular: un desafío diagnóstico y terapéutico. Rev. Argent. Dermato. 2012; 93(4).

43. Fleishmajer R, Faludi G, Krol S. Scleredema and diabetes meIlitus. Arch. Dermatol. 1970; 101:21-26.

44. Cole GW, Headley J, Skowsley R. Scleroderma diabeticorum: a common and distinct cutaneous manifestation of diabetes mellitus. Diabetes Care 1983: 6:189-192.

45. Santamaría G. Manifestaciones cutáneas de la diabetes mellitus. Rev. Fac. Med. UNAM 2003; 46(4):143-147.

46. Pastor MA, Álvarez P, Mosquera J, Bautista R. Escleredema. Actas Dermofiliofr. 2006; 97(4)287-288.

47. Ferringer T, Miller OF. Cutaneous manifestation of diabetes meIlitus. Dermatol. Clin. 2002; 20:483-492.

48. Rosenbloom AL, Silverstein JH, Kubillis PS, et al. Limited joint mobility (LJM) in insulin-dependent diabetes mellitus high risk for microvasculopathy (MVP) Pediatr. Res. 1980;14:580A.

49. Cabo H, Woscoff A, Casan J. Piel cérea y movilidad articular en pacientes diabéticos. Dermatol. Arg. 1995; 1(2):89-92.

50. Román J, Pacheco M, Andrade L. La limitación de la movilidad articular en pacientes con diabetes mellitus tipo 2. Rev. Per. Reumatol. 1999; 5(1)21-31.

51. Dependra KT, Mohan TD, Agrawal A. Estudio clínico de las dermatosis en diabetes mellitus para establecer sus marcadores. Indian J. Dermatol. 2012; 57:287-288.

52. Cabo H, Woscoff A, Casa J. Empedrado digital: marcador temprano de engrosamiento cutáneo en pacientes diabéticos. Arch. Arg. Dermatol. 1993; 43(3):185-192.

53. Huntley AC. Finger pebbles: a common finding in diabetes meIlitus. J. Am. Acad. Dermat. 1966; 14:612-617.

54. Hollister DS, Brodell RT. Finger "pebbles": a dermatologic sign of diabetes mellitus. Postgrad. Med. 2000; 41:39-41.

55. Sánchez-Pedreño P. Alteraciones cutáneas en la diabetes mellitus. Actitud diagnóstica y tratamiento. En: Tébar FJ, Escobar F. La diabetes mellitus en la práctica clínica. $1^{\circ} \mathrm{Ed}$. Buenos Aires. Médica Panamericana 2009; 43:355- 357.
56. Requena Caballero L, Martín Moreno L. Manifestaciones cutáneas de la diabetes mellitus. Revisión. Formación Médica Continua 1991; 40(950):77-93.

57. Hoerer E, Dreyfuss F, Herzerberg M. Carotenemia, skin color and diabetes mellitus. Acta Diabetol Lat 1975;12:202-207.

58. Orlandi C. Manifestaciones cutáneas de la diabetes mellitus. En: Contreras C, Ed. Diabetes Mellitus. Santiago: Editorial Mediterráneo. 2004;385-392.

59. Kahn CR, Flier Js, Bar RS, et al. The syndromes of insulin resistance and acanthosis nigricans: insulin-receptor disorder in man. N Engl. J Med.1976; 294:739-745.

60. Higgins S, Freemark M, Prose N. Acanthosis nigricans: a practical approach to evaluation and management. Dermatol. Online J 2008;14:2.

61. Dawber RPR, Bleehen SS, Vallance-Owen J. Vitiligo and diabetes mellitus. Br J Dermatol. 1971;84:600.

62. Macaron C, Winter RJ, Traisman HS, et al. Vitiligo and juvenile diabetes mellitus. Arch. Dermatol. 1977; 113:1515-1517.

63. Macaron C, Winter RJ, Traisman HS, et al. Vitiligo and juvenile diabetes mellitus. Arch. Dermatol. 1977;113:1515-1517.

64. Hann S, Chung H. Historic view of vitiligo in Korea. Int. J Dermatol. 1997; 36:313-315.

65. Taïeb A, Picardo M, et al. The definition and assessment of vitiligo: a consensus report of the Vitiligo European Task Force. Pigment Cell Res. 2007;20:27-35.

66. FerringerT, Miller O.F. Cutaneous manifestation of diabetes meIlitus. Dermatol. Clin. 2002; 20:483-492.

67. Halevy S, Feurman EJ. Abnormal glucose tolerance associated with lichen planus. Acta Derm. Venereol. 1979; 59:167-170.

68. Petrou-Amerikanou, Markopolus AK, Belazi M, et al. Prevalence of oral lichen planus in diabetes mellitus according to the type of diabetes. Oral Dis. 1998; 4:37-40.

69. Bagan JV, Donat JS, Penarrocha M, et al. Oral lichen planus and diabetes mellitus: a clinico-pathological study. Bull Group Int. Rech. Sc.i Stomatol. Odontol. 1993; 36:3-6.

70. Romero MA, Seoane J, Varela P, Diz P, García MJ. Prevalencia de diabetes mellitus en pacientes con liquen plano oral. Características clínicas-patológicas. Med. Oral. 2002; 7:121-129.

71. Giménez R, Pérez J. Liquen plano y enfermedades asociadas: estudio clínico-epidemiológico. Act. Dermatol. Sifiliog. 2004; 95(3):154-160.

72. Sánchez L, Cabanillas J, Ponce M, Salluca A. Liquen Plano. Dermatol. Per. 2011;21(1)27-43.

73. López L, Ramos JA, Petrocelli D, Manríquez A. Xantomas eruptivos como manifestación inicial de diabetes mellitus e hipertrigliceridemia severa. Rev. Cent. Dermatol. Pascua 2010, 19(1):15-18.

74. Alver R, et al. Xantomas eruptivos como primera manifestación de enfermedad sistémica. Piel, 2009; 19:243-246.

75. Villalón G, Martín JM, Monteagudo CM, Alonso V, Montesinos E, Jordá E. Xantomas eruptivos en el debut de DM. Actas Dermosifiliogr 2008; 99:426-427.

76. Nayak KR, Daly RG. Eruptive xanthomas associated with hipertrigliceridemia and new-onset diabetes mellitus. N. Engl. J. Med. 2004; 350(12):1235-1236.

77. Redondo P. Enfermedades autoinmunes de la piel y la diabetes. Av. Diabetol. 2007; 23(3):189-196.

78. Medani S, Shapiro J. Alopecia areata update. J Am. Acad. Dermatol. 2000; 42:549-566.

79. De Andrade M, Jackow CM, Dahm N, Hordinsky M, Reveille JD, Duvic M. Alopecia areata in families: association with the HLA Locus. J Invest. Dermatol. Symp. Proc. 1999; 4:220-223.

80. Wang SJ, Shohat T, Vadheim C, Shellow W, Edwuards J, Rotter JI. Increased risk for type 1 diabetes in elatives of patients with alopecia areata. Am. J Med. Genet. 1994; 51:234-23.

81. Taniyama M, Kushima $K$, Ban $Y$, et al. Simultaneous develo- 
pment of insulin dependent diabetes mellitus and alopecia areata universalis. Am. J. Med. Sci. 1991;301:269-271.

82. Kim YJ, Chong BI, Ro BI. Four year alopecia areata study. Rev. Dermatol. Ang. University South Korea 2000; 2:18-20.

83. Jacques L, Darier J. Hidradenomes éruptifs. I. Epithéliomes adenoids des glandes sudoripares ou adenomes sudoripares. Ann Dermatol. Venerol. 1887; 8:317-323.

84. Haedington JD, Koshi J, Murphy PJ. Clear cell glycogenesis in multiple syringoma. Arch. Dermatol. 1972;106:353-356.

85. Alcantara A, Mercadillo P, Hernández M, Sastre N, Ramos R. Siringoma de ceúlas claras. Estudio clínico-patológico de un caso y revisión de la literatura. Rev. Med. Hosp. Gen. Mex. 2001; 64(2):97-99.

86. Guijarro J, Bañuls J, Carnero L, Albares M, Botella R. Siringoma de células claras y diabetes mellitus. Actas Dermosifiliogr. 2001; 92:291-295.

87. Furve $\mathrm{M}$, Hori $Y$, NkabayashiY. Clear cell syringoma, association with diabetes mellitus. Am. J Dermatopathol. 1993;15:166-164.

88. Rodríguez-Peralto JL, Calzado L, Vanaclocha F. Psoriasis. e-dermatosis 2010:124:516-122.

89. Puig-Sanz L. La psoriasis, ¿una enfermedad sistémica? Actas Dermosifiliogr. 2007; 98:396-406.

90. Shapiro J, Cohen A, David M, Hodak E, Chodik G, Viner A, Kremer E, Heymann A. The association between psoriasis, diabetes mellitus and atherosclerosis in Israel: a case-control study. J Amer. Acad. Dermatol. 2007; 56(4)629-634.

91. Sentochnik D, Eliopoulos G. Infección y diabetes. En: Kahn R, et al. Joslin's Diabetes Mellitus. $14^{\circ}$ Ed. Barcelona: Lippincot Williams \& Wilkins, 2007;60:1017-1020.

92. Sasaki A, Horiuchi N, Hasegawa K, et al. Mortality and causes of death in type 2 diabetic patients: a long-term follow-up study in Osaka district, Japan. Diabetes Res. Clin. Pract. 1989;7:33-40.

93. Brayton RG, Stokes PE, Schwartz MS, et al. Effect of alcohol and various diseases on leukocyte mobilization phagocytosis and intracellular bacterial killing. N Engl. J Med. 1970; 282:123-128.

94. Mowat AG, Baum J. Chemotaxis of polymorphonuclear leukocytes from patients with diabetes mellitus. N Engl. J Med. 1971; 284:621-627.

95. Bagdade JD, Root RK, Bulger RJ. Impaired leukocyte function in patients with poorly controlled diabetes mellitus. Diabetes 1974; 23:9-15.

96. Tan JS, Anderson JL, Watanakunakorn C, et al. Neutrophil dysfunction in diabetes mellitus. J. Clin. Lab. Med. 1975; 85:26-33.

97. Dziatkowiak H, Kowalska M, Denys A. Phagocytic and bactericidal activity of granulocytes in diabetic children. Diabetes 1982; 31:1041-1043.

98. Katz S, Klein B, Elian I, et al. Phagocytic activity of monocytes from diabetic patients. Diabetes Care 1983; 6:479-482.

99. Mac Cuish AC, Urbaniak SJ, Campbel CJ, et al. Phytohemagglutinin transformation and circulating lymphocyte subpopulations in insulin-dependent diabetes patient. Diabetes 1974; 25:908-912.

100. Bonifaz A. Micología Médica Básica. México: Menéndez Editores, 2000; 3:35-95.

101. Tarango V. Dermatofitos: epidemiología y cuadros clínicos. En: Menéndez T, Hernández H. Actualidades en micología médica. $5^{\circ}$ Ed. México: Dr. Teófilo Herrera, 2011:14:115-117.

102. Alteras I, Saryt E. Prevalence of pathogenic fungi in the toewebs and toe-nails of diabetic patients. Mycopathologia 1979; 67:157-159.

103. Greene RA. Scher RK. Nail changes associates with diabetes mellitus. Dermatology 1987; 16:1015-1021.

104. Buxton P, et al. Prevalence and epidemiology of toenail onychomicosis in diabetic subjects: a multicentre survey. $\mathrm{Br}$. J. Dermatol. 1998; 139:665-671.
105. Cornsistein W, Mora A, Orellana N, Capparelii FJ, del Castillo M. Candida: epidemiología y factores de riesgo. Rev. Enferm. Infecc. Microbiol. Clin. 2013; 31(6):380-384.

106. Turunc T, Demiroglu YZ, Aliskah h, Colakoglu S, Arslan H. Eleven cases of mucormycosis with atypical clinical manifestations in diabetic patients. Diabetes Res. Clin. Pract. 2008, 82(2):203-208.

107. Zaballos P, Ara M, Pozo A, et al. Mucormicosis rinocerebral fulminante. Actas Dermosifiliogr. 2003; 94(9)624-626.

108. Utz JP, Shadomy HJ, Deep fungal infections. In: Fitzpatrick TB, Eisen $A Z$, Wolff $D$, et al, eds. Dermatology in general medicine. New York: Mc Graw-Hill 2000; 2248-2275.

109. Gabillot-Care M, Roujeau JC. Acute bacterial skin infections and cellulitis. Curr. Opin. Infect. Dis. 2007; 20:118-123.

110. Rogers RL, Perkins J. Skin and soft tissue infections. Prim Care 2006; 33:697- 710.

111. Peñaloza-Martínez JA, López Navarro A. Corinebacteriosis cutánea. Rev. Centro Derm. Pascua 2001; 3:141-146.

112. Arce M, Arenas R. Eritrasma, una revisión. Dermatología, 1997; 41(4):151-154.

113. Cabo H, Franco de Montes de Oca N, Tzovanis MC, Gallardo H. Eritrasma generalizado. Med. Cutan Ibero Lat. Am. 1983; 11:129-132.

114. Arce M, Moncada M, Arenas R. Búsqueda intencionada de eritrasma y su frecuencia relativa en la consulta del servicio de dermatología. Dermatología 1997; 41:(6):205-208.

115. Montes LF, Dobson H, Dodge BG, Knowles WR. Erythrasma and diabetes mellitus. Arch. Dermatol. 1969; 99:969-980.

116. Parra P, Pérez S, Patiño ME, Castañeda S, García J. Actualización en fascitis necrotizante. Semin. Fund. Esp. Reumatol. 2011; 20:1-8.

117. Quirk WF, Sternbach G, Joseph J. Infection with flesh eating bacteria. J Emerg. Med. 1996; 14:747-753.

118. Nowak R. Flesh-eating bacteria: Not new, but still worrisome. Science 1994; 264:1655-1658.

119. Kaul R, McGeer A, Low DE, Green K, Schwartz B. Population based surveillance for group $A$ streptococcal necrotizing fasciitis: clinical features, prognostic indicators, and microbiologic analysis o seventy-seven cases. Ontario Group A Streptococcal Study. Am J Med. 1997; 103:18-24.

120. Navarro JA. Gangrena de Fournier. Rev. Eviden. Invest. Clin. 2010; 3(1)51- 57.

121. Eke N. Fournier's gangrene: a review of 1726 cases. Br J Surg 2000; 87:718-728.

122. Ersy A, Yilmaz G, Akgun Y, CelikY. Factors affecting mortality of Fournier's gangrene: review of 70 patients. Anz. J Surg. 2007; 77:43-48.

123. Hurley HJ.The eccrine sweat glands. In: Moschella SL, Hurley HJ, eds. Dermatology. Vol. 2, $2^{\circ}$ Ed. Philadelphia:WB Saunders, 1985.

124. Calvagno M. Pie diabético. En: Diabetes Mellitus. $4^{\circ} \mathrm{Ed}$. Buenos Aires. Argentina: Librería Akadia Editorial, 1ra. Reimpresión, 2012; 33:612-627.

126. International consensus on the Diabetic Foot. By the International Working Group on the Diabetic Food. Holland, Mayo 2003

127. Giurini J. El pie diabético: Estrategias de tratamiento y prevención de las úlceras. En Kahn R. y colaboradores. Joslin's Diabetes Mellitus. $14^{\circ}$ Ed. Barcelona, España: Lippincott Williams \& Wilkins 2007; 62:1049-1060.

128. Ruiz-Morosini ML, Ferrari N. Insulinoterapia. En: Diabetes MeIlitus. $4^{\circ}$ Ed. Buenos Aires. Argentina: Librería Akadia Editorial, $1^{\circ}$ Reimpresión, 2012; 16:293-295.

129. Litt JZ. Drug eruption reference manual. New York: Parthenon Publishing; 2000

130. Kono T, Hayami M, Kobayashi $\mathrm{H}$, et al. Acarbose induced generalized erythema multiforme. Lancet 1999; 354:396-397. 